\title{
Optimasi Letak Gate dan Temperatur Cetakan Terhadap Cacat Hasil Produk Outer Shell Helmet: Sebuah Studi Numerik
}

\author{
Agung Premono ${ }^{1}$, Ragil Sukarno ${ }^{1}$, Ihsan Muazam² \\ 1) Dosen program studi pendidikan teknik mesin, Universitas Negeri Jakarta \\ 2) Alumni program studi pendidikan teknik mesin, Universitas Negeri Jakarta \\ Email: agung-premono@unj.ac.id
}

\begin{abstract}
Abstrak
Helmet merupakan salah satu alat keselamatan yang wajib digunakan oleh pengendara sepeda motor yang dihasilkan dari proses injection moulding. Banyak faktor yang mempengaruhi kualitas produk yang dihasilkan dari proses injection moulding, diantaranya adalah temperatur cetakan dan letak gate. Penelitian ini ditujukan untuk mengetahui letak gate dan temperatur cetakan yang paling optimal dalam mereduksi cacat hasil produk outer shell helmet. Studi ini dilakukan dengan simulasi menggunakan Autodesk Inventor Mold Flow. Model yang digunakan adalah outer shell helmet dengan variasi tiga gate yang berbeda yaitu (1) gate didepan bagian bawah model, (2) gate disamping model, dan (3) gate dibelakang model. Dari setiap variasi gate diberikan tiga variasi temperatur yang berbeda yaitu $50^{\circ} \mathrm{C}, 60^{\circ} \mathrm{C}$, dan $70^{\circ} \mathrm{C}$. Dengan variasi tersebut maka terdapat sembilan model yang disimulasikan dalam penelitian tersebut. Simulasi dilakukan untuk menemukan tiga jenis cacat yang sering timbul akibat letak gate dan temperatur cetakan yaitu: (1) sink mark; (2) short shot; dan (3) volumetric shrinkage. Hasil simulasi menunjukkan bahwa variasi parameter yang menghasilkan cacat paling sedikit model dengan letak gate yang berada disamping model dengan temperatur cetakan $50^{\circ} \mathrm{C}$.
\end{abstract}

Kata kunci: injection moulding, gate, temperatur cetakan,helmet.

\section{Latar Belakang}

Helmet merupakan alat keselamatan yang wajib digunakan oleh pengendara sepeda motor. Peningkatan kebutuhan helmet yang disebabkan oleh peningkatan jumlah sepeda motor memacu berbagai produsen helmet untuk menghasilkan dan memasarkan produk yang diminati oleh konsumen. Melihat fungsi helmet yang sangat penting dan beragamnya produk yang dihasilkan oleh berbagai produsen helmet, maka perlu ditelaah lebih lanjut tentang cacat produk helmet yang dapat mengakibatkan helmet kurang berfungsi maksimal maupun produktivitas dalam proses produksi helmet.

Banyak faktor yang mempengaruhi kualitas helmet. Ditinjau dari proses produksinya, maka faktor yang mempengaruhi kualitas helmet antara lain: temperatur cetakan dan letak gate. Beberapa cacat produk yang diakibatkan dari kesalahan pengaturan temperatur cetakan antara lain: Short Shot, Sink Marks, Weld Line, Flow Marks, Dull Surface, Volds in Parts, Colour Un Evenness, Burning, Fishing, Parts Distort, Silver Streaks, Laminations, Crazing, Sticking Marks, Parts Sticking in Mold[1]. Sedangkan letak gatemempengaruhi kecacatan yang disebabkan oleh overpacking/shrinkage. Pengaruh sistem ini terhadap shrinkage adalah pada proses pengisian, packing/holding/cooling, dan tekanan yang lebih merata [1].

Penentuan parameter umum dalam proses pembuatan produk plastik menggunakan proses injection moulding telah diberikan oleh beberapa perusahaan pembuat produk plastik[2]. Namun, dalam kondisi pembuatan produk yang memiliki tingkat kerumitan beragam, perlu diteliti lebih lanjut tentang penentuan parameter yang digunakan untuk proses tersebut. Beberapa peneliti telah melakukan studi tentang efek letak gate dalam proses injection moulding. Tabi dkk. [3] telah membuat studi eksperimen tentang cacat pada proses injeksi yang diakibatkan karena letak gate.Sementara itu, studi simulasi tentang pengaruh letak gate terhadap proses injeksi dilakukan oleh Babu dan Vardan [4]. Sedangkan studi simulasi penentuan letak gate dalam proses injection mouldinguntuk beberapa produk tertentu telah dilakukan oleh beberapa peneliti, antara lain: (1) untuk pembuatan connecting link telah dilakukan oleh $\mathrm{P}$ Shakkarwal dan L Yadav [5]; (2) produk bobbin [6]; dan (3) produk rumah motor [7].

Melihat pentingnya helmet sebagai alat keselamatan kendaraan bermotor, dan belum adanya peneliti yang mempublikasikan penelitian tentang parameter optimal dalam proses pembuatan komponen helmet, maka penelitian ini bertujuan untuk menentukan temperatur cetakan dan lokasi gate yang paling tepat untuk material ABS agar tidak menimbulkan cacat pada hasil produk outer shell helmet. 


\section{Teori Dasar}

Proses cetak injeksi (injection molding) adalah suatu metode pembentukan suatu part/produk dimana material (termoplastik) yang sudah dilelehkan diinjeksikan kedalam cetakan lalu didinginkan hingga mengeras[8]. Untuk membentuk sebuah produk dengan bentuk tertentu, maka mesin injection moulding perlu ditambah sebuah cetakan (mould). Cetakan (mold) merupakan suatu alat/tool yang digunakan untuk membentuk part sesuai dengan desain yang kita inginkan (bentuk \& dimensi)[8]. Definisi lainnya, cetakan (mold) merupakan suatu rongga yang memiliki bentuk tertentu (sesuai desain) agar dapat membuat suatu produk dalam waktu yang cepat dalam satu tahapan dan murah[8]. Cetakan terbentuk dari 2 bagian yaitu cavity dan core. Dalam proses injection molding, keduanya merupakan satu kesatuan yang tidak dapat dipisahkan, karena gabungan antara cavity dan core inilah yang akan membentuk desain dari sebuah komponen. Dalam proses manufaktur,cavity dan core dapat berupa satu kesatuan atau berupa bagian terpisah (ditanamkan/inserting block). Pemilihan proses manufaktur dalam membuat cetakan tergantung kepada faktor ekonomi dan desain dari benda yang akan dibuat.

ABS (Acrylonitrile Butadiene Styrene) adalah resin jenis thermoplastic yang biasa digunakan untuk aplikasi mesin injection molding[9]. Plastik ABS adalah copolymer dari Acrylonitrile, Butadiene, dan Styrene, dan secara umum memiliki kekuatan sedang. Secara umum sifat ABS adalah: (1) memiliki kekuatan sedang; (2) tangguh, keras dan kaku; (3) daya tahan terhadap bahan kimia yang bagus; (4) memiliki stabilitas dimensi yang baik; (5) tahan terhadap creep; (6) electroplatable; (7) memilkiki sifat pembentukan yang mudah; (8) memiliki tingkat kekuatan benturan yang sangat tinggi; dan (9) memiliki kekuatan tarik dan kekakuan yang tinggi. Selain sifat tersebut, ABS memiliki kelemahan, yaitu: (1) ketahanan terhadap cuaca yang rendah; (2) ketahanan terhadap pelarut yang rendah; dan (3) menghasilkan asap yang banyak ketika dipanaskan.

Cacat produk cetakan berbahan ABS dipengaruhi oleh banyak faktor diantaranya adalah kekurangsesuaian temperatur cetakan dan letak gate. Kedua faktor tersebut menyebabkan adanya lima cacat produk yang sering ditemukan dalam produk cetakan, yaitu: (1) Short Shot; (2) Sink Mark; dan (3) volumetric shrinkage[10]. Sink Marks adalah lekukan atau lubang yang tidak sesuai pada permukaan dari hasil produk. Sink marks biasanya disebabkan oleh material yang belum terisi penuh kedalam part karena gate yang telah membeku atau packing/holding pressure terlalu rendah. Short shot adalah jenis cacat yang paling jelas terlihat dalam proses injection molding yang ditandai dengan hasil produk yang belum terisi penuh oleh resin/material[10].Volumetric shrinkage adalah persentase reduksi geometris dari sebuah part dari akhir fase packing/cooling sampai ketika part selesai didinginkan (cooled) pada nominal temperatur standar yaitu $25^{\circ} \mathrm{C} / 77^{\circ} \mathrm{F}$.

\section{Metode Penelitian}

Studi tentang efek temperatur cetakan dan letak gate terhadap cacat produk outer shell helmet dilakukan secara simulasi menggunakan perangkat lunak Autodesk Inventor Moldflow 2013. Selain perangkat lunak tersebut, solidwork 2014 juga digunakan untuk menggambar model outer shell helmet. Model yang digunakan dalam studi tersebut dapat dilihat pada gambar 1 dengan dimensi panjang $280 \mathrm{~mm}$, lebar $254 \mathrm{~mm}$, tinggi $275 \mathrm{~mm}$, dan tebal $2 \mathrm{~mm}$. Variasi lokasi gatediletakkan pada tiga lokasi yang biasa digunakan pada produk injection molding, yaitu (1) didepan bagian bawah model, (2) disamping model, dan (3)dibelakang model. Variasi ini dimaksudkan untuk mencari letak gate terbaik untuk produk outer hell helmet agar menghasilkan kualitas produk terbaik. Adapun gambar masing-masing variasi gate dapat dilihat pada gambar 2 . 

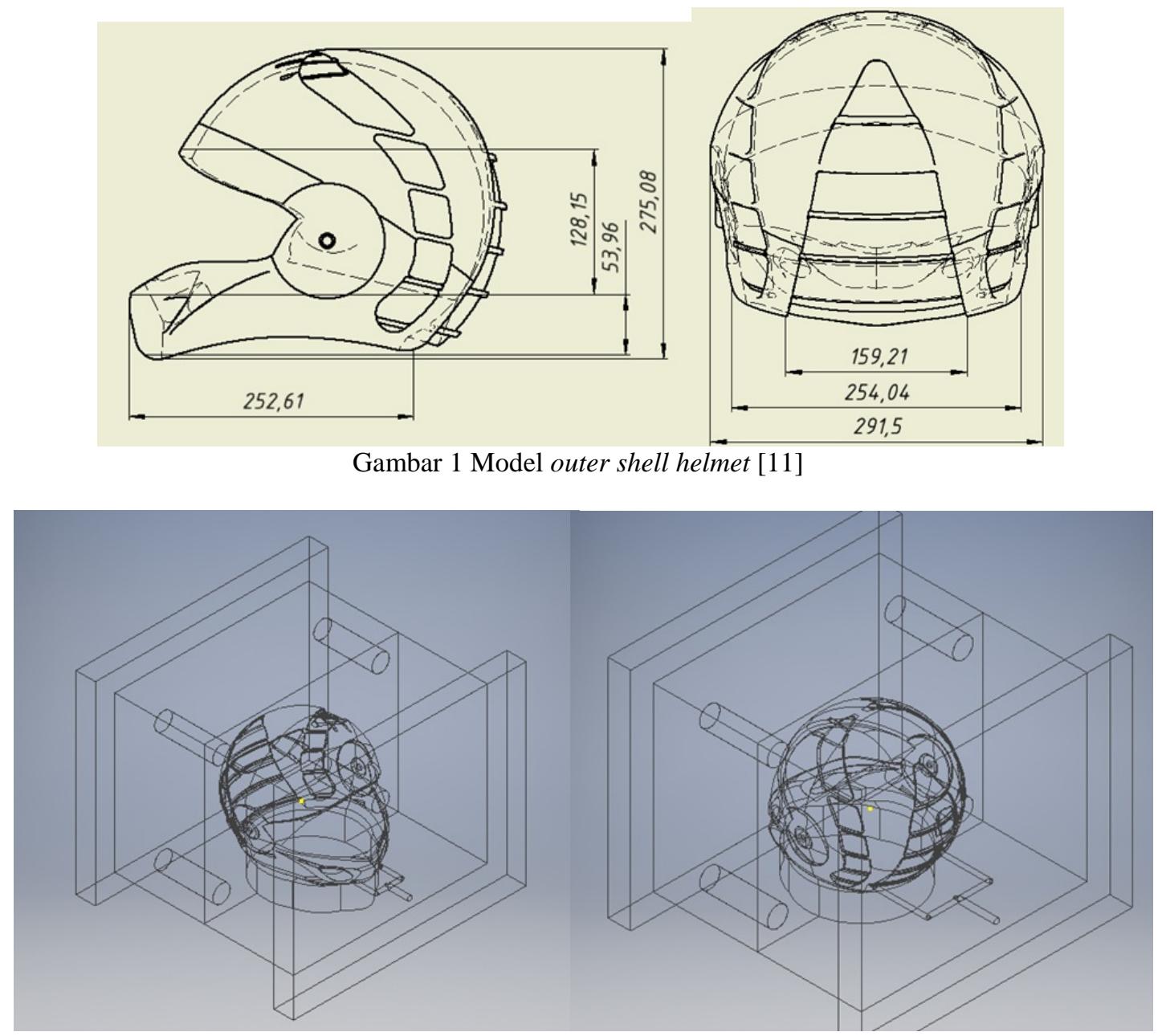

(a)(b)

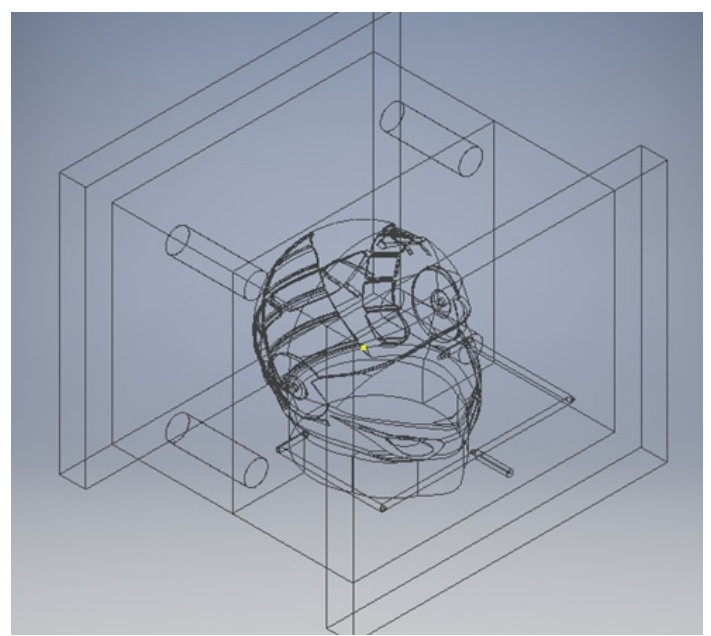

(c)

Gambar 2 Desain gate yang terletak pada:(a) bagian depan; (b) bagian belakang; dan (c) bagian tengah; dari model outer shell helmet[11]

Temperatur cetakan pada proses simulasi diberikan dengan tiga variasi temperatur yang berbeda untuk setiap model yang memiliki perbedaan letak gate. Ketiga temperatur tersebut adalah $50^{\circ} \mathrm{C}, 60^{\circ} \mathrm{C}$, dan $70^{\circ} \mathrm{C}$. Pemilihan temperatur mengacu pada karakteristik material 
ABS serta nilai acuan proses injeksi yang dilakukan di perusahaan pembuatan produk outer shell helmet. Komposisi tiga jenis letak gate yang berbeda dengan tiga perbedaan temperatur menghasilkan sembilan varian model. Kesembilan model tersebut terangkum dalam tabel 1.

Tabel 1 Varian model outer shell helmet [11]

\begin{tabular}{|c|c|}
\hline Varian & Letak gate, temperatur cetakan \\
\hline Varian 1 & Gate 1 , Mold Temperature $50^{\circ} \mathrm{C}$ \\
\hline Varian 2 & Gate 1 , Mold Temperature $60^{\circ} \mathrm{C}$ \\
\hline Varian 3 & Gate 1 , Mold Temperature $70^{\circ} \mathrm{C}$ \\
\hline Varian 4 & Gate 2 , Mold Temperature $50^{\circ} \mathrm{C}$ \\
\hline Varian 5 & Gate 2 , Mold Temperature $60^{\circ} \mathrm{C}$ \\
\hline Varian 6 & Gate 2, Mold Temperature $70^{\circ} \mathrm{C}$ \\
\hline Varian 7 & Gate 3 , Mold Temperature $50^{\circ} \mathrm{C}$ \\
\hline Varian 8 & Gate 3, Mold Temperature $60^{\circ} \mathrm{C}$ \\
\hline Varian 9 & Gate 3, Mold Temperature $70^{\circ} \mathrm{C}$ \\
\hline
\end{tabular}

\section{Hasil dan Pembahasan}

Meshing yang digunakan dalam proses simulasi adalah global edge length sebesar 2 mm dengan merge tolerance $0,1 \mathrm{~mm}$. Hasil simulasi yang dianalisis dalam studi ini adalah: (1) shink mark index; (2) shink mark estimate; (3) short shot; dan (4) volumetric shrinkage.
Hasil simulasi menunjukkan beberapa perbedaan sink mark yang terjadi akibat adanya perbedaan letak gate dan temperatur cetakan. Hasil tersebut dapat dilihat pada grafik 1. Grafik menunjukkan bahwa sink mark terendah dengan angka 6,345 \% dihasilkan pada model dengan letak gate pada bagian tengah dengan temperatur cetakan $50^{\circ} \mathrm{C}$.

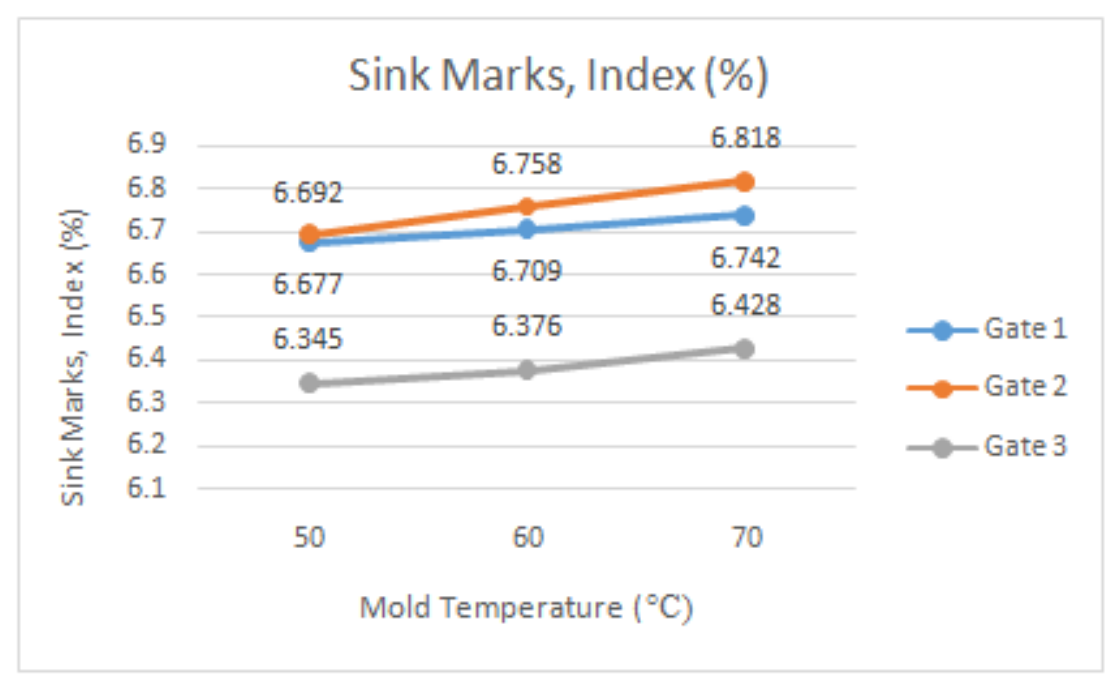

Grafik 1 Sink marks index [11] 
Selain shink mark index, cacat shink mark juga dapat dilihat pada shink mark estimate yang dihasilkan dari analisis komputasi. Hasil shink mark estimate dapat dilihat pada grafik 2 .
Grafik tersebut menunjukkan bahwa estimasi sink mark terkecil terdapat pada model dengan letak gate pada bagian tengah dengan temperatur cetakan $50^{\circ} \mathrm{C}$.

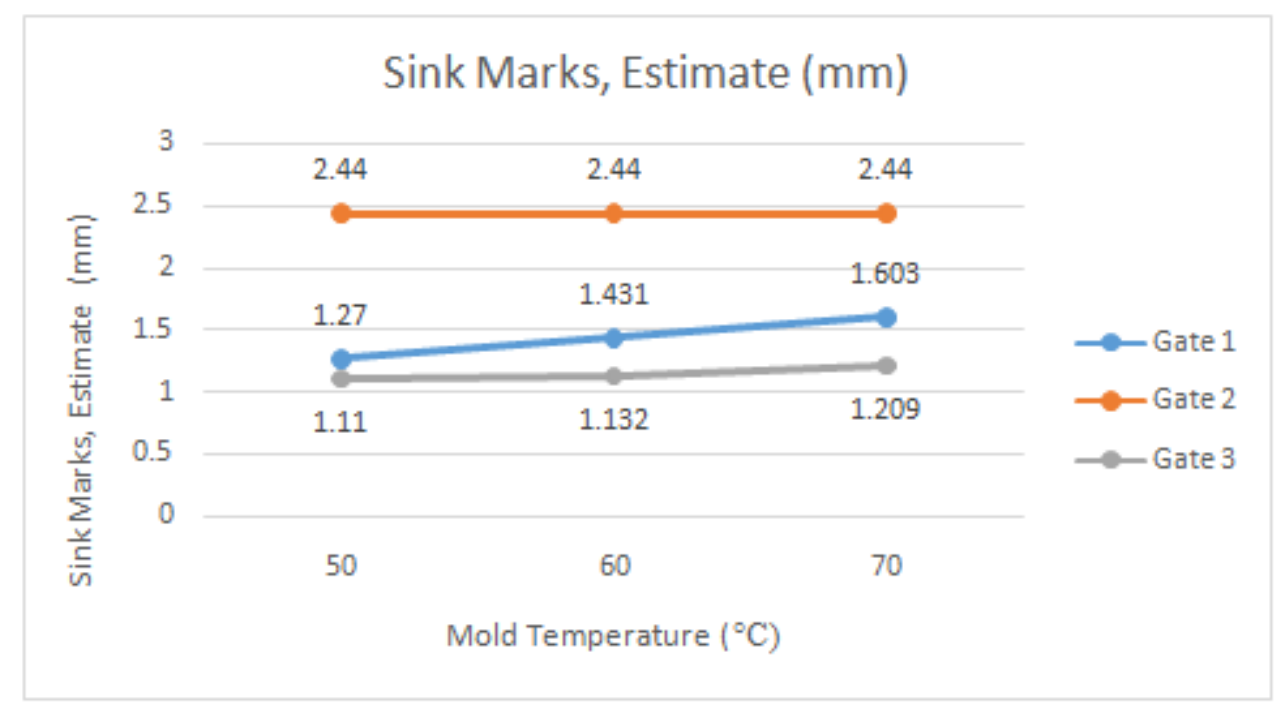

Grafik 2 Sink Marks Estimate[11]

Grafik 1 dan 2 menunjukkan bahwa model yang menghasilkan cacat sink mark terkecil adalah model dengan letak gate pada bagian tengah model dengan temperatur cetakan $50^{\circ} \mathrm{C}$. Hal ini disebabkan karena letak gate pada bagian tengah dengan temperatur yang tidak terlalu tinggi memungkinkan material mengisi cetakan secara lebih merata sebelum material tersebut mengeras sehingga sink mark bisa dikurangi.

Cacat hasil cetakan yang paling mudah dilihat adalah short shot. Hasil simulasi menunjukkan adanya short shot pada model dengan letak gate bagian depan dengan temperatur cetakan $50 \mathrm{C}$ dan model dengan letak gate pada bagian belakang model pada temperatur cetakan 60 dan 70 C. Sedangkan untuk model dengan letak gate pada bagian samping model tidak menghasilkan cacat short shot di semua variasi temperatur cetakan yang diberikan. Hasil cacat tersebut seperti ditunjukkan pada gambar 3.

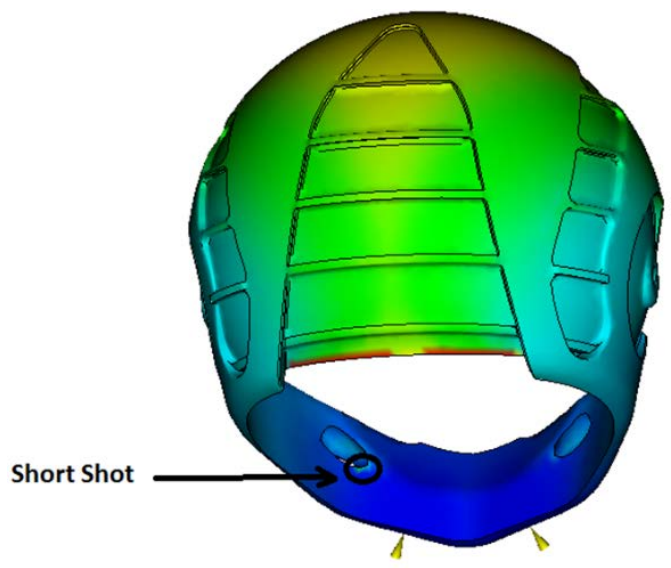

(a)

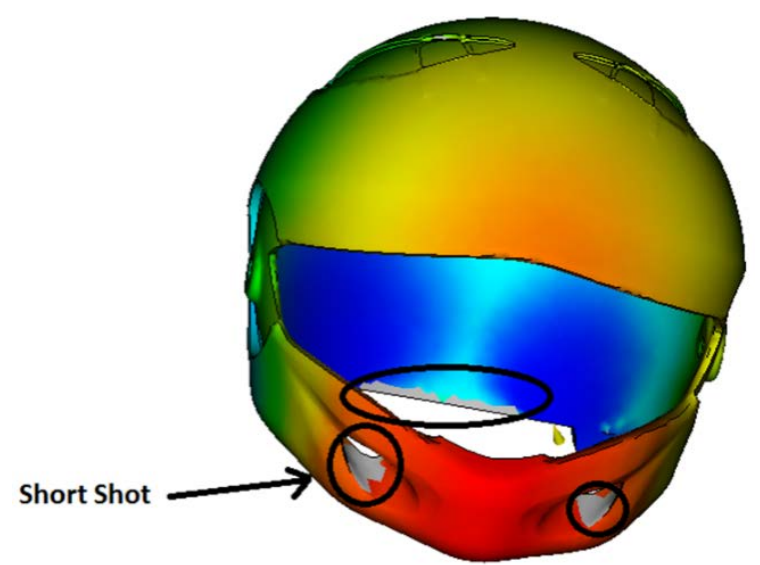

(b) 


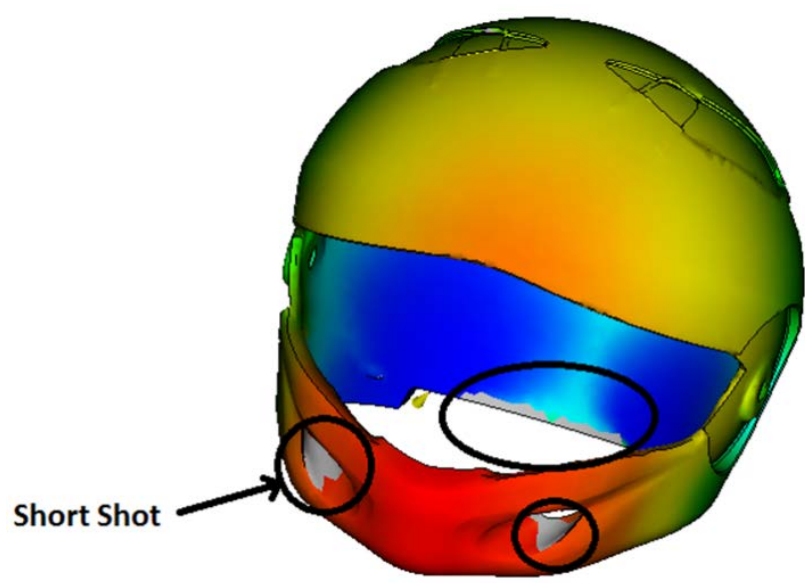

(c)

Gambar 3 Cacat Short shot yang terjadi pada model dengan: (a) letak gate di bagian depan dan temperatur cetakan 50 C; (b) letak gatedi bagian belakang dan temperatur cetakan 60 C; dan (c) letak gatedi bagian belakang dan temperatur cetakan 70 C.[11]

Hasil simulasi untuk volumetric shrinkage akibar perbedaan letak gate dan temperatur cetakan dapat dilihat pada grafik 3.

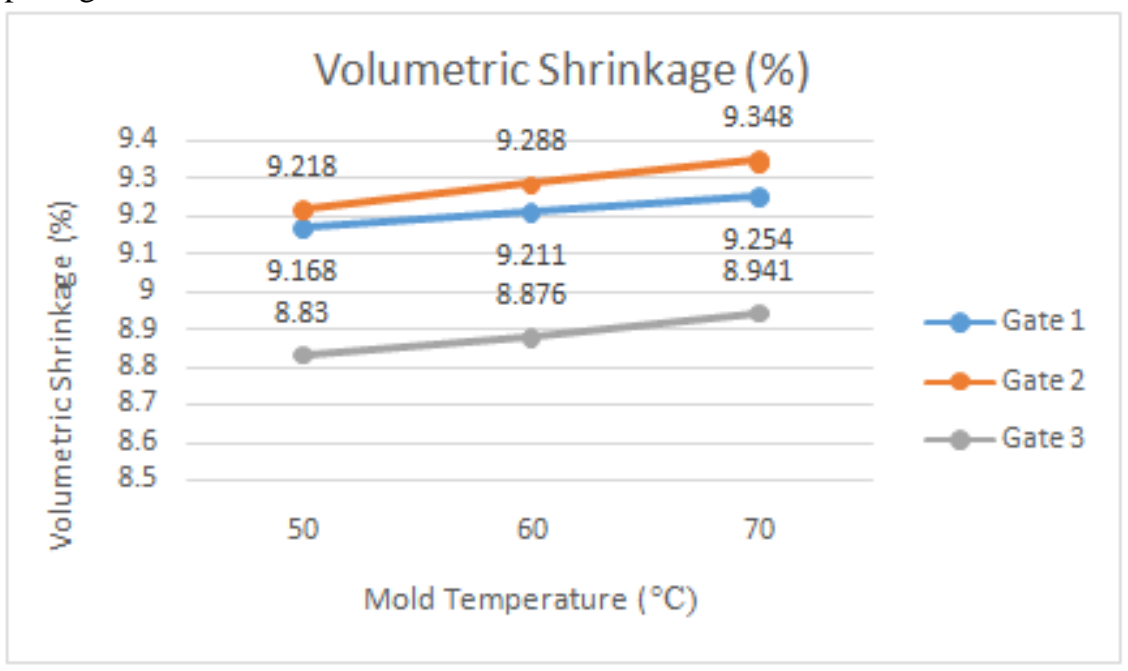

Grafik 3 Volumetric shrinkage [11]

Grafik diatas memperlihatkan temperatur cetakan yang rendah akan mempercepat proses pendinginan (rapid cooling) yang akhirnya akan mempersingkat proses pengerutan/shrinkage. Sementara itu, letak gate pada bagian tengah memungkinkan material melaju lebih merata ke dalam cetakan sehingga volumetric shrinkage dapat dikurangi. Kedua kondisi inilah yang menghasilkan volumetric shrinkage terendah dihasilkan pada varian dengan Gate 3 (bagian tengah model) dengan temperatur cetakan $50^{\circ} \mathrm{C}$.

\section{Simpulan}

Hasil simulasi injection molding outer shell helmet dengan dimensi panjang $280 \mathrm{~mm}$, lebar $254 \mathrm{~mm}$, tinggi $275 \mathrm{~mm}$, dan tebal $2 \mathrm{~mm}$ didapatkan pada model dengan letak gate pada bagian tengah dan temperatur cetakan $50 \mathrm{C}$ (varian model 7). Hasil simulasi cacat produk yang diperoleh dari model tersebut adalah (1) volumetric shrinkage $=8,83 \%$; (2) sink marks, index $=6,345 \%$; dan (3) sink marks, estimate = 1,11 mm. Selain ketiga indikator tersebut, model dengan varian letak gate pada bagian 
tengah dan temperatur $50 \mathrm{C}$ tidak ditemukan adanya cacat short short.

\section{Ucapan Terima Kasih}

Terima kasih disampaikan kepada PT. PT. Murni Cahaya Pratama, Indonesia yang telah berkenan memberikan ijin pengambilan data awal penelitian.

\section{Daftar Pustaka}

[1] Rao, Natti S., Design Formulas For Plastics Engineers 2nd Edition. Munich: Hanser Gardner Publications, Inc, 2004.

[2] Rees, Herbert. Understanding Injection Mold Design. Munich: Hanser Gardner Publications, Inc, 2001

[3] T. Tabi, A. Suplicz, F. Szabo, N.K. Kovacs, B. Zink, H. Hargitai, J.G. Kovacs, "The analysis of injection molding defects caused by gate vestiges", express polymers letters vol. 9 No. 4 pp. 394-440, 2015

[4] P. Hussain Babu dan T. Vishnu Vardan, "Computer simulation for finding optimum gate location in plastic injection moulding process", International Journal of Engineering Research and Applications, Vol. 3 Issue 6, pp. 947 - 950 Nov - Dec 2013.
[5] P Shakkarwal dan L Yadav, "Design and mould flow analysis of injection mould for connecting link", International journal on emerging technology 4(1): 182-185, 2013

[6] Y. Kumar K.R, dan Nagaraja R., "Significance of mold filling analysis for finding optimal gate location in injection molding process for bobbin", International journal of scientific and research publication, vol. 4, issue 4, April 2014

[7] Raghavendra N, Pramod R Sharma, and M $\mathrm{C}$ Math, A design and moulding analysis of two plate mould tool for motor rare housing thermoplastic product”, European journal of advances in engineering and technology, 2 (3): 90-95, 2015

[8] Rosato, Dominick, V. Injection Molding Handbook 3rd Edition. Boston: Kluwer Academic Publishers, 2000.

[9] Shoemaker, Jay. Moldflow Design Guide 1st Edition. Framingham: Moldflow Corporation, 2006.

[10] Suharto. Pengetahuan Dasar Metode Cetak Injeksi. Jakarta: LP3M Mandiri, 2009.

[11] I. Muazam, "Simulasi pengaruh letak gate dan temperatur cetakan terhadap hasil prosuk outer shell helmet”, Skripsi, Universitas Negeri Jakarta, 2015 (tidak dipublikasikan). 